\title{
Risk Factors in Hepatocellular Carcinoma
}

\section{Naga Anusha $P^{*}$}

Department of Biotechnology, Sri Y.N. College, Andhra University, Narsapur, India

\begin{abstract}
Hepatocellular carcinoma is the fifth most common cancer in the world. The aim of this study was to identify the possible risk factors causing HCC. Certain metabolic diseases like hepatitis B. Hepatitis C infection lead to liver cancer without causing liver cirrhosis and increases risk of HCC by 27 fold. Cirrhosis itself is an independent risk factor of inducing HCC by 5 -fold. Drugs used for the treatment of diabetes have shown to cause HCC. Certain toxins like aflatoxins increase the risk of liver cancer. Anabolic steroids are known to cause HCC by mimicking the action of some hormones. Some of organic and inorganic compounds like vinyl chloride and Arsenic cause HCC. This article summarize the risk factors of Hepato Cellular Carcinoma.
\end{abstract}

Keywords: Hepatocellular Carcinoma; Liver cancer; Hepatitis B; Hepatitis C; Diabetes; Aflatoxin; Steroids; Smoking; Vinyl Chloride; Arsenic

Abbreviations: THCC: Hepato Cellular Carcinoma; LC: Liver Cancer; $\mathrm{As}_{2} \mathrm{O}_{3}$ : Arsenic Trioxide; As: Arsenic; HBV: Hepatitis B Virus; HCV: Hepatitis C Virus; HBsAg: Hepatitis B Surface Antigen; TP53: Tumor protein 53; CYP1A2: Cytochrome 450 1A2; CYP3A4: Cytochrome 450 3A4; GSTP1: Glutathione S-transferase P

\section{Introduction}

Liver cancer (LC) ranks fifth in frequency in the world. In developing countries, incidence rates are two- to three-fold higher than in developed countries [1]. Hepatocellular carcinoma, like any other cancer, develops when there is a mutation to the cellular machinery that causes the cell to replicate at a higher rate and results in the cell growth avoiding apoptosis [2]. In particular, chronic infections of hepatitis B, C can aid the development of hepatocellular carcinoma by repeatedly causing the body's own immune system to attack the liver cells, some of which are infected by the virus, others merely bystanders $[3,4]$.

The early detection of HCC is highly desirable, patients with this disease are often asymptomatic and consequently HCC is frequently diagnosed late, by which time it is often untreatable [5]. Suspicion of disease may first arise in patients with liver cirrhosis who develop ascites, encephalopathy or jaundice [6]. Some patients initially present with upper abdominal pain, weight loss, early satiety or a palpable mass in the upper abdomen. Other symptoms include obstructive jaundice, diarrhea, bone pain, dyspnoea, intraperitoneal bleeding, paraneoplastic syndromes [e.g. hypoglycemia, erythrocytosis, hypercalcemia, severe watery diarrhea, or cutaneous features].

\section{Causes for Hepatocellular Carcinoma}

The causes for hepatocellular carcinoma are unknown but several risk factors were identified:

- Chronic hepatitis B and C infection

- Cirrhosis of the liver

- Diabetes mellitus

- Exposure to toxins, such as certain types of fungi (aflatoxin), vinyl chloride, anabolic steroids, and arsenic

- Smoking

\section{Chronic Hepatitis B and $C$ infection}

Hepatitis B and C virus (HBV \& HCV) may be one of the agents involved in the etiology of human primary liver cancer [7]. This hypothesis is supported by the similarity between the geographical distribution of chronic carriers of the viral surface antigen ( $\mathrm{HBsAg}$ ) and that of hepatocellular carcinoma (HCC), but not all the viruses were related to risk [8]. Researchers have previously identified eight genotypes of $\mathrm{HBV}$ and a variety of mutations in two regions of the viral genome are associated with liver cancer. People who have hepatitis B virus face up to a 100 fold increased risk of developing HCC $[9,10]$. HBsAg which is present in the people infect with hepatitis virus is known to play important role in developing HCC $[11,12]$. There were some epidemiological indications of an association between HBV infection and hepatocellular carcinoma are supported by the detection of HBV markers such as HBsAg or viral DNA sequences, although in a non-integrated form in tumor tissue [13]. HBsAg is known to activate oncogenes such as cmyc and that HBsAg could "transform" nontumorigenic cell lines into lines capable of growing as tumors in nude mice which supported the hypothesis that HBsAg play an important role in pathogenesis of $\mathrm{HBV}$ associated liver cancer $[14,15]$.

\section{Cirrhosis of the Liver}

Usually, individuals at risk for developing liver cancer are those with cirrhosis (advanced liver disease with permanent liver scarring) [16]. In other words, cirrhosis is a precancerous condition. In fact, patients with cirrhosis regardless of the underlying cause are at increased risk of developing liver cancer [17]. Cirrhosis increases the risk of developing liver cancer by at least 40 times over the risk of an average person. Of all people with cirrhosis, 3 percent will develop liver cancer every year. A good percentage of alcoholics will eventually develop cirrhosis that has increased risk of HCC $[18,19]$. Cirrhotic liver contains various kinds of hepatocellular nodules, including HCC the hepatocel-

*Corresponding author: Naga Anusha Puvvada, Department of Biotechnology Sri Y.N. College, Narsapur, India, E-mail: anushanpuvvada@gmail.com

Received November 05, 2011; Accepted December 14, 2011; Published December 15, 2011

Citation: Naga Anusha P (2011) Risk Factors in Hepatocellular Carcinoma. J Cancer Sci Ther S17. doi:10.4172/1948-5956.S17-009

Copyright: ( 2011 Naga Anusha P. This is an open-access article distributed under the terms of the Creative Commons Attribution License, which permits unrestricted use, distribution, and reproduction in any medium, provided the original author and source are credited. 
lular nodules which were divided into adenomatous hyperplasia, atypical adenomatous hyperplasia [20]. These nodules were known to cause HCC $[21,22]$.

\section{Diabetes Mellitus}

Several studies have suggested that diabetes mellitus may alter the risk of developing a variety of cancers, and the associations are biologically plausible [23]. The relation between diabetes and cancer mortality is still under studies. Diabetes is associated with alterations in liver metabolism and immune response that may influence post-operative recovery and long-term survival after hepatectomy for cancer [24]. Patients with type I or type II diabetes mellitus submitted to a potentially curative hepatic resection for metastatic colorectal cancer were identified from the prospective database, and compared with patients with hepatic colorectal metastases submitted to resection during the same time interval, but without diabetes mellitus [25]. Cancer patients who already have diabetes have a greater chance of dying of the disease than cancer patients who do not have the blood-sugar disorder [26]. The risk of liver cancer is common in people with diabetes who are heavy drinkers and who may or may not have hepatitis. Insulin made by the pancreas moves through the portal vein to the liver and exposes the liver to high levels of the insulin hormone. Non-alcoholic fatty liver disease, cirrhosis and abnormal fat retention are diabetes-related factors that increase the risk of liver cancer. Obesity is a shared risk factor for both diabetes and liver cancer $[27,28]$.

Several confounding factors, having general or site-specific relevance assess cancer risk in diabetic patients. These factors include diabetes duration, varying levels of metabolic control, different drugs used for therapy, and the possible presence of chronic complications $[29,30]$. Hyperinsulinemia most likely favors cancer in diabetic patients as insulin is a growth factor with pre-eminent metabolic but also mitogenic effects, and its action in malignant cells is favored by mechanisms acting at both the receptor and post-receptor level [31,32]. Insulin's mitogenic action is specifically involved in the higher incidence of liver cancer in diabetic patients since healthy liver cells are physiologically exposed to higher insulin concentrations than other tissues [33,34]. The three major oral anti-diabetic drug families' sulphonylureas, biguanides, and thiazolidinediones have a different mechanism of action. Sulphonylureas stimulate endogenous insulin secretion, while the other two categories of compounds are insulin sensitizers, i.e. they make tissues more responsive to insulin and, therefore, decrease hyperinsulinemia [35]. If Hyperinsulinemia plays a role in increasing cancer risk and progression in diabetic patients, it is reasonable to expect that these drugs will have a different effect on association between diabetes and cancer [36,37].

\section{Aflatoxin}

Aflatoxin represents a group of secondary fungal metabolites which were discovered as contaminants of certain lots of animal feeds. These compounds have a high order of acute toxicity to animal species, and have been shown to possess potent carcinogenic properties in several animal species [38,39]. Aflatoxin forms adducts with DNA and with proteins, and these are the direct products of (or surrogate markers for) damage to a crucial, cellular macromolecular target. Aflatoxin B1 undergoes an initial two-electron oxidation by the cytochrome P450family members CYP1A2 and CYP3A4, yielding aflatoxin-B1-8,9oxide [40]. This epoxide reacts with the $N 7$ atom of guanine to form a pro-mutagenic DNA adduct (aflatoxin-N7-guanine). The aflatoxinDNA adduct is unstable and undergoes depurination, leading to its urinary excretion which act as a biomarker. Several mutational assays have shown that aflatoxins induce mainly G-T transversions. A G-T transversion mutation in codon 249 of the TP53 tumor-suppressor gene results in a loss of function, and this mutation has been found in $~ 50 \%$ of patients with HCC $[41,42]$.

\section{Vinyl Chloride}

Vinyl chloride is associated with liver cancer in humans and has been classified as a Group 1 carcinogen by IARC, Category 1 (carcinogenic to man) by the EU and a Group A carcinogen (carcinogenic to humans) by the EPA (EPA, 1987) $[43,44]$. Occupational vinyl chloride exposure was first associated with development of liver cancer in 1974, when rare liver angiosarcomas were detected in three workers who worked in a vinyl chloride polymerization plant [45]. This is known to cause liver cancer in infants and younger ones. Vinyl chloride produces DNA adducts and has been positive in gene mutation and chromosomal aberration assays [46]. Chromosomal aberrations have also been observed in peripheral lymphocytes of exposed workers in some studies. The mutations caused by vinyl chloride are different from those of sporadic liver cancers. The mutations caused by vinyl chloride have been found in p53 and Ki-ras genes [47].

\section{Anabolic Steroids in Liver Cancer}

Anabolic steroids are technically known as Anabolic-Androgen steroids [48]; these steroids mimic the effects of some hormones and increase protein synthesis in the cells particularly in muscles [49-51]. High doses of oral steroids can cause liver damage as they are metabolized in the digestive system increasing bioavailability and stability [52-55]. Steroids are known to cause hepatic adenomas which are not cancerous but it is dangerous as this causes serious bleeding in the liver when they are ruptured [56-59]. C17 alpha alkylated compounds, like Anadrol 50 can lead to stressed liver, even liver damage and very rare cases lead to liver cancer $[60,61]$.

\section{Arsenic in Liver Cancer}

Liver cancers can develop from specific chronic liver diseases. Epidemiology studies have clearly indicated an association between chronic arsenic exposure and abnormal liver function, hepatomegaly, hepatoportal sclerosis, liver fibrosis and cirrhosis [62]. Arsenic is well absorbed from the gastrointestinal tract, and first reaches the liver. Arsenate is reduced to arsenite in the liver by glutathione which detoxifies it [63]. Liver is rich in glutathione; it is a major site of arsenic detoxication, either from glutathione acting as an antioxidant, or by glutathionearsenic conjugation for cellular efflux and biliary excretion. Arsenic trioxide $\left(\mathrm{As}_{2} \mathrm{O}_{3}\right)$ is a novel anticancer agent in inducing HCC. $\mathrm{As}_{2} \mathrm{O}_{3}$ is used in the complete remission in acute promyelocytic leukemia patients who were refractory to conventional chemotherapy or all-trans retinoic acid. The role of arsenic in the treatment of this unique form of leukemia is still under investigation [64,65]. Arsenic compounds have been tested in other hematological malignancies in vitro. It is not known at present whether these compounds will prove useful in the treatment of solid tumors. Arsenic trioxide causes cancer by methylation of $\mathrm{CpG}$ islands in promoter region of p16 RASSF1A, E Cadherin and GSTP1 genes [66]. Experimental studies with cell lines have showed that high concentration of $\mathrm{As}_{2} \mathrm{O}_{3}$ causes methylation of the above genes and thus induces cancer [67].

\section{Smoking}

Smoking of tobacco is practiced worldwide by over one thousand million people. Tobacco is most commonly smoked as cigarettes; both 
manufactured which are a highly sophisticated nicotine delivery system and hand-rolled [68]. Pipes, cigars, bidis and other products are used to a lesser extent or predominantly in particular regions. Smoking cigarettes increases the liver damage caused by a common chronic liver disease, hepatitis C. There is a statistically significant and dose dependent association between tobacco smoking and HBsAg negative HCC [69]. Smoking mainly induces p53 mutations which lead to HCC and other type of cancers. Apart from hepatocarcinoma smoking mainly induces lung cancer [70], cancers in nasal cavities, paranasal sinus, nasopharynx, stomach cancer, cervical cancer, kidney cancer, Myeloid leukemia, etc. Lung cancer is the most common of all the cancers and all the investigations have showed a clear cut response relationship between the amounts smoked daily [71,72]. The smoke released by cigars is a complex mixture of several hundred of different molecules which include several carcinogens such as polycyclic aromatic hydrophobic compounds or N-nitrosamines. Benzopyrenes remains has highly carcinogenic compound known [73].

\section{Conclusion}

HCC is one of the commonest cancers worldwide. It is a major health problem and its incidence is increasing day by day. The presence of cirrhosis is the major risk factor and worldwide this is largely due to chronic HCV and HBV infection. HCC carcinogenesis is likely to involve interplay of viral, environmental and host factors. The advent of mass-vaccination programmes for hepatitis B is beginning to reduce prevalence rates for HCC in some countries, but for the most part, HCV-related HCC is increasing. Concerted strategies need to be developed for HCC surveillance in at risk populations. Further studies should be undertaken to assess the specific risk factors in detail.

\section{References}

1. Harring TR, Kuten DA, Nguyen NT, Goss JA, O'Mahony CA (2011) Orthotopic Liver Transplantation in Patients with Mixed Hepatocellular CarcinomaCholangiocarcinoma. J Transplant Technol Res 1:104.

2. Sapisochin G, Charco R (2011) Salvage Liver Transplantation for HCC: An Old Story without Consensus? J Transplant Technol Res 1:106e.

3. F Xavier Bosch, Josepa Ribes, Joan Borràs (2007) Epidemiology of Primary Liver Cancer. Semin Liver Dis 19: 271-285.

4. Lins Kusterer LE (2011) Oral Diseases and Liver Pre and Post-Transplantation Disorders. J Transplant Technol Res S1:001

5. Sangro B, Iñarrairaegui M (2011) Radioembolization for Hepatocellular Carcinoma: Evidence-Based Answers to Frequently Asked Questions. J Nucl Med Radiat Ther 2: 110.

6. Sudhakar A (2009) History of Cancer, Ancient and Modern Treatment Methods J Cancer Sci Ther 1: 1-4.

7. Perz JF, Armstrong GL, Farrington LA, Hutin YJ, Bell BP (2006) The contributions of hepatitis $B$ virus and hepatitis $C$ virus infections to cirrhosis and primary liver cancer worldwide. J Hepatol 45: 529-538.

8. Wang WL, London WT, Feitelson MA (1991) Hepatitis B $x$ Antigen in Hepatitis B Virus Carrier Patients with Liver Cancer. Cancer Res 51: 4971-4977.

9. Singh RK, Sudhakar A, Lokeshwar BL (2011) From Normal Cells to Malignancy: Distinct Role of Pro-inflammatory Factors and Cellular Redox Mechanisms. J Cancer Sci Ther 3: 70-75

10. Ramsey SE, Engler PA, Stein MD, Brown RA, Cioe P, et al. (2011) Effect of CBT on Depressive Symptoms in Methadone Maintenance Patients Undergoing Treatment for Hepatitis C. J Addict Res Ther 2: 109.

11. Edman JC, Gray P, Valenzuela P, Rall LB, Rutter WJ (1980) Integration of hepatitis $B$ virus sequences and their expression in a human hepatoma cell. Nature 286: 535-538.

12. Ettorre GM, Vennarecci G, Santoro R, Miglioresi L, Lepiane P, et al. (2011)
Experiences in Hepatic Surgery and Transplantation after Radioembolization. J Nucl Med Radiat Ther 2: 109.

13. Brechot C, Pourcel C, Louise A, Rain B, Tiollais P (1980) Presence of integrated hepatitis B virus DNA sequences in cellular DNA of human hepatocellular carcinoma. Nature 286: 533-535.

14. Mukherjee S (2009) Antiviral Therapy for Hepatitis B in Preand Post-liver Transplant Patients. J Antivir Antiretrovir 1: 17-27.

15. Ishikawa T, Ishibashi J, Yamashita K, Dalkhsuren SO, Sumida K, et al. (2009) Non-thermal Effects of Far-Infrared Ray (FIR) on Human Hepatocellular Carcinoma Cells HepG2 and their Tumors. J Cancer Sci Ther 1: 78-82.

16. Nellithady GS, Anila K, Kumar KK, Kaveri H (2010) Lack of Association of Chronic Liver Disease in Patients with Oral Lichen Lanus. J Carcinogene Mutagene 1:113

17. Cariani E, Lasserre C, Seurin D, Hamelin B, Kemeny F, et al. (1988) Differential Expression of Insulin-like Growth Factor II mRNA in Human Primary Liver Cancers, Benign Liver Tumors, and Liver Cirrhosis. Cancer Res 48: 6844-6849.

18. Kinami Y, Takashima S, Miyazaki I (1986) Hepatic resection for hepatocellular carcinoma associated with liver cirrhosis. World J Surg 10: 294-300.

19. Liu CY, Chang LC, Yang SW (2011) Metastatic Hepatocellular Carcinoma to the Nasal Cavity: A Case Report and Review of the Literature. J Cancer Sci Ther 3: 081-083.

20. Castellanos MI, Seijas OR, González D, Ronquillo M, del Rosario Abreu M, et al. (2011) Immune Alterations in Liver Cirrhosis: Its Relationship with Etiology, Child Pugh Stage and Malnutrition. J Nutrition Disorder Ther 1: 101.

21. Yu MW, Hsu FC, Sheen IS, Chu CM, Lin DY, et al. (1997) Prospective Study of Hepatocellular Carcinoma and Liver Cirrhosis in Asymptomatic Chronic Hepatitis B Virus Carriers. Am J Epidemiol 145: 1039-1047.

22. Li H, Wang G, Wang A, Tong W, Zhang Y (2011) Alcohol Consumption and Risk of Type 2 Diabetes in Mongolian Population, Inner Mongolia, China. J Diabetes Metab 2:116.

23. Kaneko M, Suzuki H, Watanabe H, Oda E, Aizawa Y (2011) Metabolic Syndrome is a Poor Predictor of Incident Diabetes Compared with Hemoglobin A1c (Hba1c) in a General Japanese Population. J Diabetes Metab S: 2.

24. Ramachandra S (2011) Do we need yet another Insulin? J Diabet Metabol 2 0 e4.

25. Hans-Olov Adami, Joseph McLaughlin, Anders Ekbom, Christian Berne, Debra Silverman (1991) Cancer risk in patients with diabetes mellitus. Cancer Causes and Control 2: 307-314.

26. Takasaki S (2011) Mitochondrial Haplogroups Associated with Japanese Centenarians, Alzheimer's Patients, Parkinson's Patients, Type 2 Diabetes Patients, Healthy Non-Obese Young Males, and Obese Young Males . J Proteomics Bioinform 4: 106-112.

27. Kablan A, Saunders RA, Szkudlarek-Mikho M, Chin JB, Bosio RM, et al. (2010) Prieurianin Causes Weight Loss in Diet-Induced Obese Mice and Inhibits Adipogenesis in Cultured Preadipocytes. J Diabetes Metab 1: 101.

28. Shanker JH, Mahmood SE, Joshi MC, Shaifali I (2011) Obesity Indices amongs Diabetics in an Urban Population of Western Nepal. J Diabetes Metab 2: 134.

29. Adami HO, Chow WH, Nyrén O, Berne C, Linet MS, et al. (1996) Excess Risk of Primary Liver Cancer in Patients With Diabetes Mellitus. J Natl Cancer Inst 88: $1472-1477$.

30. Ali ZH (2011) Health and Knowledge Progress among Diabetic Patients afte Implementation of a Nursing Care Program Based on Their Profile. J Diabetes Metab 2: 121.

31. El Asrar MA, Adly AAM, El Hadidi E, Gharib M (2011) Serum and Urinary Nitrites and Nitrates and Doppler Sonography in Detection of Early Diabetic Complications. J Diabetes Metab 2: 117.

32. Florez H, Scranton R, Farwell WR, DeFronzo RA, Ezrokhi M, et al. (2011) Randomized Clinical Trial Assessing the Efficacy and Safety of BromocriptineQR when Added to Ongoing Thiazolidinedione Therapy in Patients with Type 2 Diabetes Mellitus. J Diabetes Metab 2: 142.

33. La CV, Negri E, Franceschi S, D'Avanzo B, Boyle P (1994) A case-control study of diabetes mellitus and cancer risk. $\mathrm{Br} \mathrm{J}$ Cancer 70: 950-953.

34. Chen D, Huang H, Xing Y, Liu Y, Xu Y, et al. (2011) A New Vanadium Complex 
Improves the Spatial Learning and Memory by Activation of Caveolin-MAPK CREB Pathway in Diabetic Mice. J Diabetes Metab 2: 114.

35. Samadi N, Safavi M, Mahmoodi M (2011) Impact of Quality of Life Education on Self-Concept among Type 2 Diabetes Patients. J Diabetes Metab 2: 132.

36. Paolo V, Francesco F, Laura S, Giuseppe, Riccardo V (2009) Diabetes and cancer. Endocr Relat Cancer 16: 1103-1123.

37. Heymann MC, Hofmann SR (2011) Novel Inflammasomes and Type I Diabetes, Intestinal Inflammation and Psoriasis as Newly InflammasomeRelated Diseases. J Genet Syndr Gene Ther S3: 001.

38. Kensler TW, Qian GS, Chen JG, Groopman JD (2003) Translational Strategies for Cancer Prevention In Liver. Nat Rev Cancer 3: 321-329.

39. Vitin AA, Martay K, Vater Y, Dembo G, Maziarz M (2010) Effects of Vasoactive Agents on Blood Loss and Transfusion Requirements During Pre-Reperfusion Stages of the Orthotopic Liver Transplantation. J Anesthe Clinic Res 1:104.

40. Shank RC, Wogan GN, Gibson JB, Nondasuta A (1972) Dietary aflatoxins and human liver cancer. II. Aflatoxins in market foods and foodstuffs of Thailand and Hong Kong. Food and Cosmetics Toxicology 10: 61-69.

41. Wogan GN (1966) Chemical nature and biological effects of the aflatoxins Bacteriol Rev 30: 460-470.

42. Naga Deepthi $\mathrm{CH}, \mathrm{VVL}$ Pavan Kumar A, Rameshbabu, Indirapriyadarshin $U$ (2011) Role of Tumor Suppressor Protein p53 in Apoptosis and Cancer Therapy. J Cancer Sci Ther S17: 001.

43. Berk PD, Martin JF, Young RS, Creech J, Selikoff IJ, et al. (1976) Vinyl chlorideassociated liver disease. Ann Intern Med 84: 717-731.

44. Burrill J, Hafeli U, Liu DM (2011) Advances in Radioembolization - Embolics and Isotopes. J Nucl Med Radiat Ther 2: 107.

45. L Simonato, KA L'Abbe, A Andersen, S Belli, P Comba (1991) A collaborative study of cancer incidence and mortality among vinyl chloride workers. Scand J Work Env iron Health 17:159-169.

46. Lewis R, Rempala G, Dell LD, Mundt KA(2003) Vinyl chloride and liver and brain cancer at a polymer production plant in Louisville, Kentucky. J Occup Environ Med 45:533-537.

47. Boffetta P, Matisane L, Mundt KA, Dell LD (2003) Meta-analysis of studies of occupational exposure to vinyl chloride in relation to cancer mortality. Scand J Work Environ Health 29: 220-229.

48. Uesaka M, Imamura T (2011) Cell - to Species-Level Diversity of Epigenetic Setting for Androgen Receptor Expression in Mammals. J Steroids Hormon Sci S2: 004.

49. Falk H, Thomas LB, Popper H, Ishak KG (1979) Hepatic angiosarcoma associated with androgenic-anabolic steroids. Lancet 2: 1120-1123.

50. Yadav M, Durga P, Gopinath R (2011) Role of Steroids in Prevention of Pain on Propofol Injection. J Anesthe Clinic Res 2: 132

51. Bahar I, Vinker S, Kaiserman I (2011) The Effect of Topical Steroids on Blood Glucose Profile in Diabetic Patients. J Clinic Experiment Ophthalmol 2: 133.

52. T M Creagh, A Rubin, D J Evans (1988) Hepatic tumours induced by anabolic steroids in an athlete. J Clin Pathol 41: 441-443.

53. Minuth WW, Denk L, Glashauser A (2010) Promoting and Harmful Effects of Steroid Hormones on Renal Stem/Progenitor Cell Development. J Tissue Sci Eng 1: 101.

54. Feng J, Zheng SL, Liu W, Isaacs WB, Xu J (2011) Androgen Receptor Signaling in Prostate Cancer: New Twists for an Old Pathway. J Steroids Hormon Sci S2: 001.

55. Bowen RS, Ferguson DP, Lightfoot JT (2011) Effects of Aromatase Inhibition on the Physical Activity Levels of Male Mice. J Steroids Hormon Sci S1: 001.

56. Pavlová S, Vašiček D, Kotwica J, Sirotkin AV (2010) Involvement of Cell Cycle and Apoptosis-Related Protein p21 in Control of Secretory Activity of Porcine Ovarian Cells. J Steroids Hormon Sci 1: 102

57. Persons KS, Hareesh S, Eddy VJ, Ray R(2010)Liposomal 1,25-dihydroxyvitamin D3-3-bromoacetate is a Stronger Growth-inhibiting Agent than its unencapsulated Counterpart in Prostate Cancer Cells. J Steroids Hormon Sci 1 : 101.
58. Su C, Rybalchenko N, Schreihofer DA, Singh M, Abbassi B, et al. (2011) Cell Models for the Study of Sex Steroid Hormone Neurobiology. J Steroids Hormon Sci S2: 003.

59. Reebye V, Kim J, Frilling A, Nicholls JP, Habib NA, et al. (2011) The Interplay between the Androgen Receptor, Soluble Factors and Tumour Microenvironment. J Steroids Hormon Sci S2: 002

60. Søe KL, Søe M, Gluud C (1992) Liver pathology associated with the use of anabolic-androgenic steroids. Liver 12: 73-79.

61. Johnson HM, Noon-Song E, Ahmed CM (2011) Controlling Nuclear Jaks and Stats for Specific Gene Activation by Ifny and Other Cytokines: A Possible Steroid-like Connection. J Clin Cell Immunol 2: 112.

62. Cui X, Wakai T, Shirai Y, Yokoyama N, Hatakeyama K (2006) Arsenic trioxide inhibits DNA methyltransferase and restores methylation-silenced genes in human liver cancer cells. Hum Pathol 37: 298-311.

63. Liu J, Waalkes MP (2008) Liver is a target of arsenic carcinogenesis. Toxico Sci 105: 24-32.

64. Yang CH, Kuo ML, Chen JC, Chen YC (1999) Arsenic trioxide sensitivity is associated with low level of glutathione in cancer cells. Br J Cancer 81: 796799.

65. Jaiswal S (2011) Role of Rhizobacteria in Reduction of Arsenic Uptake by Plants: A Review. J Bioremed Biodegrad 2: 126.

66. Chiu HF, Ho SC, Wang LY, Wu TN, Yang CY (2004) Does arsenic exposure increase the risk for liver cancer? J Toxicol Environ Health A 67: 1491-1500.

67. Jamale T, Hase NK, Dalvi V (2011) Acute Kidney Injury Due to Arsenic Contained in Alternative Medicines in the Setting of Adult Nephrotic Syndrome. J Clinic Toxicol 1: 101

68. Mori M, Hara M, Wada I, Hara T, Yamamoto K (2000) Prospective study of hepatitis $\mathrm{B}$ and $\mathrm{C}$ viral infections, cigarette smoking, alcohol consumption, and other factors associated with hepatocellular carcinoma risk in Japan. Am J Epidemiol 151: 131-139.

69. Vineis P, Alavanja M, Buffler P, Fontham E, Franceschi S (2004) Tobacco and cancer: recent epidemiological evidence. J Natl Cancer Inst 96: 99-106.

70. Kikawa KD, Noah T, Ahwah SM, Pardini RS (2011) Docosahexaenoic Acid (DHA) Induces P53-Dependent Growth Inhibition in Transformed Colon and Lung Cell Lines Expressing Wildtype P53. J Cancer Sci Ther 3: 1-4

71. La Vecchia C, Negri E, D’Avanzo B, Boyle P, Franceschi S (1990) Medica history and primary liver cancer. Cancer Res 50: 6274-6277.

72. Yu Y, Yang M, Sansgiry SS, Essien EJ, Abughosh S (2011) Beliefs in Effectiveness of Various Smoking Cessation Interventions among Chinese Adult Smokers. Epidemiol 1: 106.

73. Abughosh S, Wu IH, Peters RJ, Essien EJ, Crutchley R (2011) Predictors of Persistent Waterpipe Smoking Among University Students in The United States. Epidemiol 1: 102 